\title{
A novel locus for syndromic chronic idiopathic intestinal pseudo-obstruction maps to chromosome $8 q 23-q 24$
}

\author{
Alessia Deglincerti ${ }^{1,7}$, Roberto De Giorgio ${ }^{2}$, Kivanc Cefle $^{3}$, Marcella Devoto ${ }^{4,5}$, \\ Tommaso Pippucci ${ }^{1}$, Giovanni Castegnaro ${ }^{1}$, Emanuele Panza ${ }^{1}$, Giovanni Barbara ${ }^{2}$, \\ Rosanna F Cogliandro ${ }^{2}$, Zeynel Mungan ${ }^{6}$, Sukru Palanduz ${ }^{3}$, Roberto Corinaldesi ${ }^{2}$, \\ Giovanni Romeo ${ }^{1}$, Marco Seri*, ${ }^{*}$ and Vincenzo Stanghellini ${ }^{2}$
}

\begin{abstract}
${ }^{1}$ Laboratory of Medical Genetics, Department of Internal Medicine, Cardioangiology and Hepatology, University of Bologna, Bologna, Italy; ${ }^{2}$ Department of Internal Medicine and Gastroenterology, University of Bologna, Bologna, Italy; ${ }^{3}$ Division of Medical Genetics, Department of Internal Medicine, Istanbul Medical Faculty, Istanbul University, Istanbul, Turkey; ${ }^{4}$ Division of Human Genetics, The Children's Hospital of Philadelphia, University of Pennsylvania, Philadelphia, PA, USA; ${ }^{5}$ Dipartimento di Medicina Sperimentale, Università La Sapienza, Roma, Italy; Division of Gastroenterology, Department of Internal Medicine, Istanbul Medical Faculty, Istanbul University, Turkey
\end{abstract}

Chronic idiopathic intestinal pseudo-obstruction (CIIP) is a rare and severe clinical syndrome characterized by symptoms and signs of intestinal occlusion, in the absence of any mechanical obstruction of the gut lumen. In the attempt to identify the genetic basis of CIIP, we analyzed a Turkish pedigree with a high degree of consanguinity in which three siblings presented with a syndromic form of CIIP. All affected family members were characterized by recurrent, self-limiting subocclusive episodes, long-segment Barrett esophagus, and a variety of minor cardiac valve or septal defects. In some patients full-thickness intestinal biopsy samples were obtained and tissues were processed for immunohistochemistry using antibodies to different markers of the intestinal neuromuscular tract. Full-thickness biopsies of the gut wall showed abnormalities of both the neural and muscular components suggesting an underlying intestinal neuromyopathy. Blood samples were collected for DNA extraction from each available family member and DNAs were genotyped using 382 microsatellites spanning the entire genome with the aim to take advantage of the homozygosity mapping approach. Linkage analysis identified a new syndromic locus on chromosome 8q23-q24 (multipoint LOD score $=5.01$ ). Our data strongly support the presence of a new genetic locus associated with CIIP, long-segment Barrett esophagus, and cardiac involvement on chromosome 8.

European Journal of Human Genetics (2007) 15, 889-897; doi:10.1038/sj.ejhg.5201844; published online 9 May 2007

Keywords: chronic intestinal pseudo-obstruction; Barrett esophagus; chromosome 8q23-q24

\footnotetext{
*Correspondence: Dr M Seri, Dipartimento di Medicina Interna, Cardioangiologia ed Epatologia, Università degli Studi di Bologna, UO Genetica Medica, Policlinico SOrsola-Malpighi, Via Massarenti, 9, 40138 - Bologna, Italy. Tel: + 39051 4292010/ 051 306474;

Fax: + 390516364004 ; E-mail: marco.seri@unibo.it

${ }^{7}$ Current address: Department of Neurology and Neuroscience, Weill Medical College of Cornell University, New York, NY, USA

Received 3 August 2006; revised 3 March 2007; accepted 4 April 2007; published online 9 May 2007
}

Introduction

Digestive motility is a complex and highly co-ordinated process that enables the digestion and absorption of the ingesta as well as its continuous mixing and propulsion. Severe congenital or acquired motor abnormalities may cause a functional obstruction of the alimentary tract, determining various different pathological conditions such as achalasia, hypertrophic pyloric stenosis, Hirschsprung disease, and intestinal pseudo-obstruction syndromes. ${ }^{1-4}$ 
Intestinal pseudo-obstruction is a rare disease characterized by a disruption of intestinal motility, ultimately leading to severe impairment of intestinal propulsion, which mimics mechanical obstruction in the absence of any lesion occluding the lumen. ${ }^{2,5-8}$ Although pseudoobstructive syndromes may be acute (subsequent to abdominal surgery, peritonitis, infections, hypokaliaemia, retroperitoneal hemorrhage, spinal or pelvic trauma, or myocardial infarction), they are more frequently chronic and can be further classified as either 'secondary' to various pathological conditions (eg metabolic and/or endocrine dysfunctions) or 'idiopathic' (chronic idiopathic intestinal pseudo-obstruction CIIP). Two main forms of CIIP are recognized, respectively labeled as myogenic (when smooth muscle cells are affected) or neurogenic (when caused by abnormalities of the enteric nervous system). ${ }^{8,9}$

Most patients do not show familial recurrence (sporadic cases) but syndromic autosomal-dominant, ${ }^{10,11}$ autosomalrecessive, ${ }^{12}$ and $\mathrm{X}$-linked ${ }^{13,14}$ forms have been described. In particular, an X-linked locus has been mapped to the Xq28 region. ${ }^{13}$ Genes involved in other intrinsic neuropathies, namely in Hirschsprung disease, such as GDNF (glial-cell line derived neurotrophic factor), GFRA1 (GDNF receptor- $\alpha_{1}$ ), EDN3 (endothelin 3), EDNRB (endothelin 3 receptor $\mathrm{B}$ ), and $S O X 10$, have not shown any mutation at least in one family with autosomal-dominant CIIP. ${ }^{15}$ Although both familial and sporadic CIIP have been widely reported, so far only few genes have been identified as responsible for syndromic CIIP: the thymidine phosphorylase gene $(T P$, also known as endothelial cell growth factor1 , ECGF1), ${ }^{16}$ the DNA polymerase- $\gamma$ gene $(P O L G)^{17}$ and SOX10. ${ }^{18}$

In the present study we mapped, using the homozygosity mapping approach, a novel gene responsible for the clinical entity presenting in a Turkish family with a syndromic form of CIIP characterized by megaduodenum, long-segment Barrett esophagus, and cardiac abnormalities.

\section{Materials and methods The family}

The family has been described in our previous report. ${ }^{19}$ To better characterize the spectrum of clinical manifestations identifiable in the affected individuals, we updated the main clinical features of the available patients and collected additional information concerning other affected relatives within the family. Blood samples $(10 \mathrm{ml})$ were collected and stored from 22 family members after a consent form was signed by each participant in the study or in the case of minors by their parents. The study has been approved by our local Ethic Committee.

\section{Tissue processing}

To characterize further the nature of the underlying intestinal dysmotility we analyzed available intestinal full-thickness specimens from few affected family members (ie, IV-9 and IV-10). Small bowel (either jejunum or/and ileum) specimens taken from nine age- and sex-matched patients with uncomplicated, non-obstructive bowel cancer were used as controls. Both pathological and control specimens were fixed in $10 \%$ buffered formalin, embedded in paraffin, cut with a microtome at 3-4 $\mu \mathrm{m}$ and stained with hematoxylin and eosin for routine histopathology. For immunohistochemistry, tissue sections were dehydrated through graded ethanol, washed thoroughly in phosphate-buffered saline (PBS, $\mathrm{pH}$ 7.4) and finally processed for immunohistochemistry using protocols widely validated in our laboratory. ${ }^{20}$ The antisera applied were directed to general neuronal (ie, neuron-specific enolase (NSE) and neurofilaments (NF)), enteroglial (protein S-100) (each one purchased from DakoCytomation, Milan, Italy) markers and to a variety of neurotransmitters/ neuromodulators, including vasoactive intestinal polypeptide (antibody code: 7913), substance P/related tachykinins (8701), neuropeptide Y (8711), calcitonin gene-related peptide (4901) (kindly donated by Dr C Sternini and HE Wong, Center for Ulcer Research and Education/Digestive Diseases Center, UCLA School of Medicine, Los Angeles, CA, USA) and neuronal nitric oxide synthase (nNOS) (purchased from BD Biosciences, San Jose, CA, USA). To explore possible abnormalities of neuronal cell survival, we used a specific antibody (purchased from DakoCytomation, Milan, Italy) directed to the product of B-cell lymphoma-2 (bcl-2), a gene encoding a protein involved in cellular pathways of neuronal apoptosis. ${ }^{21}$ A decreased Bcl-2 expression suggests a cellular commitment towards apoptosis. Specific antibodies against Kit and $\alpha$-actin (purchased from DakoCytomation, Milan, Italy) were used to identify interstitial cells of Cajal, and smooth muscle cells, respectively. Tissue sections were analyzed by a light transmission microscope (Olympus AX 70, Melville, NY, USA). Specificity studies included control experiments commonly applied in immunohistochemical protocols.

In three members of the family with clear endoscopic evidence of long-segment Barrett esophagus, mucosal biopsies obtained in the metaplastic mucosa (extending in all three cases over the distal $18 \mathrm{~cm}$ of the esophagus ${ }^{19}$ ) were processed for routine pathology.

\section{Genetic mapping}

DNA was extracted from blood samples using standard protocols. A genome-wide scan was performed to identify the disease locus taking advantage of the high degree of consanguinity within the family (homozigosity mapping). In particular, since the disease recurs in this family with an autosomal-recessive mode of inheritance, we expected the carrier parents of the patients to be heterozygous for a haplotype largely shared within the family and the affected children to be homozygous for the same haplotype. 
We started the search by analyzing the central nucleus of the family composed of three affected individuals, two unaffected siblings and two consanguineous parents (individuals III-6, III-7, IV-6, IV-7, IV-9, IV-10, IV-11 on the pedigree) (Figure 1). Using standard protocols, we amplified by PCR the 382 microsatellite markers, spaced at 10cM intervals, from the ABI PRISM linkage-mapping set version 2 (Applied Biosystems, Foster City, CA, USA). Amplified markers were electrophoresed on an ABI 3730 DNA capillary sequencer and analyzed with the GENEMAPPER software (Applied Biosystems, Foster City, CA, USA). Subsequently, to characterize specific critical regions, we extended the analysis to other individuals in the family (ie, members genotyped in Figure 1). For the purpose of LOD-score analysis, the disease was modeled as a fully penetrant autosomal recessive trait, with a frequency of the disease allele of 0.001 . To calculate two-point and multi- point LOD scores in the genome wide scan for the central nucleus of the family, we used the GeneHunter program. ${ }^{22}$ The Pedcheck program ${ }^{23}$ was used for the detection of Mendelian inconsistencies. Haplotypes were reconstructed by means of the GeneHunter program and recombination events were visualized against the family tree with the Haplopainter program. ${ }^{24}$

For the analysis of the entire family, two-point LOD scores were generated using the MLINK program of the LINKAGE package, ${ }^{25}$ and multipoint LOD scores were calculated using the SIMWALK2 program. ${ }^{26}$ Marker allele frequencies have been estimated from all genotyped family members. Genetic map location and distance for the known markers were taken from the Marshfield Clinic genetic map (http://research.marshfieldclinic.org/genetics/ GeneticResearch/compMaps.asp). Physical map location for the new chromosome 8 markers (Table 1) was obtained

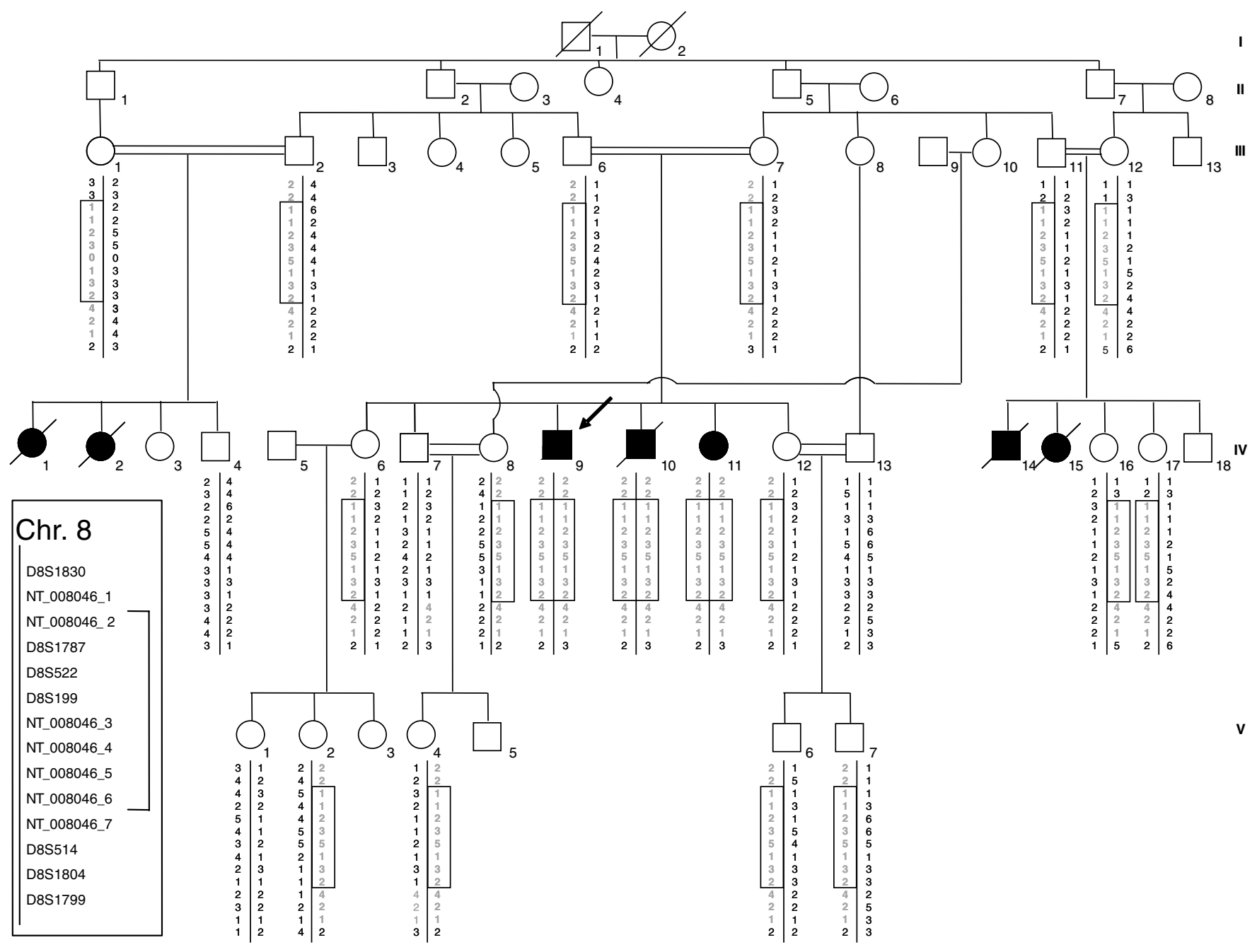

Figure 1 The Turkish pedigree showing the autosomal recessive recurrence of the familial form of syndromic CIIP complicated with Barrett esophagus and cardiac involvement. Genotyped members are those with haplotypes for the region 8 q23-q24. Arrow in IV-9 indicates the proband. Boxes indicate the critical interval inside the region of homozygosity. 
from www.ensembl.org. Genetic map location for these new markers was interpolated based on physical distance using a $1.29 \mathrm{cM}: 1 \mathrm{Mb}$ relationship, estimated in this region of chromosome 8 from the Marshfield Clinic genetic map data.

\section{Exclusion of candidate genes}

To exclude candidate genes involved in this syndromic form of CIIP, we studied three genes (ie, SLC3OA8, COLEC10, and SNTB1) by direct sequencing of all coding exons and flanking intronic regions.

\section{Results}

\section{Clinical evaluation}

Figure 1 illustrates the pedigree of the family investigated whose clinical features have been summarized in Table 2 . Three siblings (IV-9, IV-10, IV-11) presented with the whole clinical picture of this syndromic form of CIIP including typically recurrent, self-limiting subocclusive episodes, megaduodenum, long-segment Barrett esophagus, cardiac abnormalities (ie, multiple valve or septal defects with trivial functional effects), growth retardation as well as other minor pathological conditions that were not invariably present in all patients. Their parents are healthy first-degree cousins.

Since the original report was published, one of the three siblings (IV-10) died at 29 years of age due to complications of a surgical procedure prompted by intestinal perforation, while he was on total parenteral nutrition. His main clinical features can be summarized as follows: he presented with episodes suggestive of intestinal obstruction since childhood (11 years of age) and underwent repeated abdominal surgeries, although extensive investigation failed to detect any structural obstacle to transit. Upper gastrointestinal endoscopy and related histology showed long-segment Barrett esophagus $(18 \mathrm{~cm})$ without dysplasia. Radiologic tests showed delayed gastric emptying, megaduodenum, dilation of small intestine with air-fluid levels during acute episodes. Esophageal manometry showed aperistalsis and lack of any detectable pressure at the lower esophageal sphincter. A diagnosis of

Table 1 New markers not previously described used in the refinement of the critical region

\begin{tabular}{|c|c|c|c|}
\hline Marker & Primers (forward and reverse) & $\begin{array}{l}\text { Number of alleles } \\
\left({ }^{a}\right)\end{array}$ & $\begin{array}{l}\text { From base... to base... on chromosome. } 8 \\
\text { (according to the UCSC database) }\end{array}$ \\
\hline NT_008046_1 & $\begin{array}{l}\text { 5'- GCTTGTATITTGAGGTCCCC -3' } \\
\text { 5'- AAGAGCCTTTCTGGAAGGTC -3' }\end{array}$ & 5 & $109343276 . .109343522$ \\
\hline NT_008046_2 & $\begin{array}{l}\text { 5'- TGAATGCTTTGGATAGATAC - } 3^{\prime} \\
5^{\prime}-\text { CTTGAGCTGATGATCATATAGGC - } 3^{\prime}\end{array}$ & 6 & $112194539 . .112194744$ \\
\hline NT_008046_3 & $\begin{array}{l}\text { 5'- TGACATATGGCAGGATGCGG -3' } \\
5^{\prime} \text { - CTCCTTTTATGTCCAAGCTGC - } 3^{\prime}\end{array}$ & 5 & $121169470 . .121169740$ \\
\hline NT_008046_4 & $\begin{array}{l}5^{\prime}-\text { AACACATGAAAAAATGCATGCG - } 3^{\prime} \\
5^{\prime} \text { - TAGATAAGCTTGCAGTGAAAG - } 3^{\prime}\end{array}$ & 5 & $121415971 . .121416071$ \\
\hline NT_008046_5 & $\begin{array}{l}\text { 5'- TGGCCTTGACACAGTGCG - } 3^{\prime} \\
5^{\prime}-\text { AGAACATAAGTGCTCTAGGGC - } 3^{\prime}\end{array}$ & 3 & $121836515 . .121836706$ \\
\hline NT_008046_6 & $\begin{array}{l}\text { 5'- CATAGAAAAATGCATCACAAGC -3' } \\
5^{\prime} \text { - TTATCACTGCAAGCACCTCCAC -3' }\end{array}$ & 4 & $122055257 . .122055376$ \\
\hline NT_008046_7 & $\begin{array}{l}\text { 5'- TATAGACGAATGGCTTGAGTCC -3' } \\
5^{\prime} \text { - GTAGTAAGGAACCTATTGGC - } 3^{\prime}\end{array}$ & 4 & $122431607 . .122431920$ \\
\hline
\end{tabular}

As identified in the family analyzed in this study.

Table 2 Synopsis of main clinical features of the investigated family members (see text for details)

\begin{tabular}{|c|c|c|c|c|}
\hline Family member & Gastrointestinal features & Cardiac features & Other relevant clinical features & Outcome \\
\hline $\mathrm{IV}-1,{ }^{\mathrm{a}} \mathrm{F}$ & Diarrhoea, recurrent abd. distension/ pain & Unknown & Unknown & Died at 14 years \\
\hline $\begin{array}{l}\text { IV-2, } \mathrm{F} \\
\text { IV-9, M }\end{array}$ & Diarrhoea, recurrent abd. distension/pain & Unknown & Unknown & Died at 15 years \\
\hline (proband) & CIIP, megaduodenum, long Barrett & Multiple valve/septal defects & Growth retardation & Alive at 28 years \\
\hline IV-10, M & CIIP, megaduodenum, long Barrett & Multiple valve/septal defects & Growth retardation & Died at 29 years \\
\hline IV-11, F & CIIP, megaduodenum, long Barrett & Multiple valve/septal defects & Growth retardation & Alive at 30 years \\
\hline IV $-14^{a}, M$ & CIIP & Unknown & Unknown & Died at 19 years \\
\hline $\mathrm{IV}-15^{\mathrm{a}}, \mathrm{F}$ & CIIP & Unknown & Unknown & Died at 15 years \\
\hline $\mathrm{V}-4, \mathrm{~F}$ & One acute abd. pain attack & None & Growth retardation & Alive at 4 years \\
\hline $\mathrm{V}-5, \mathrm{M}$ & No obvious digestive symptoms & None & Hyperkinetic behaviour & Alive at 18 years \\
\hline
\end{tabular}

Note: abd., abdominal; F, female; M, male; CIIP, chronic idiopathic intestinal pseudo-obstruction; yrs., years.

${ }^{a}$ Clinical details in these members were obtained indirectly from clinical records. 
membranous interventricular septal defect was made by cardiac ultrasonography.

His brother (IV-9) is a 28-year-old man with a similar longlasting history of multiple hospitalizations and surgical procedures due to recurrent subocclusive episodes. He was also characterized by virtually identical findings at upper gastrointestinal endoscopy and esophageal manometry. However, his clinical features also included otosclerosis, glaucoma, and epilepsy. A recent attempt to perform small bowel manometry failed since the manometric tube did not proceed beyond an overdistended descending duodenum and was retropelled into the esophagus suggesting uncoordinated contractility of the upper gastrointestinal tract. Cardiac abnormalities included pulmonary and tricuspid valve insufficiency. Unlike his brother he responded favorably to medical therapy initially represented by domperidone $(40 \mathrm{mg} /$ day), intermittent antibiotics and more recently by tegaserod ( $12 \mathrm{mg} /$ day) and proton pump inhibitors. This medical treatment further decreased the frequency of acute episodes and, as a result, antibiotic therapy was stopped. In the interval between subocclusive episodes he still complained of epigastric pain and postprandial fullness which worsened when off therapy.

Their sister (IV-11) is a 30-year-old woman with an apparently milder form of CIIP characterized only by sporadic radiologically confirmed subocclusive episodes (ie, air-fluid levels in distended bowel loops). Digestive symptoms are associated with malnutrition and amenorrhea. Endoscopy revealed long-segment Barrett esophagus $(14 \mathrm{~cm})$, intragastric bezoars, and megaduodenum. Functional tests provided results similar to those observed in her affected brothers, namely delayed gastric emptying and severe dysmotility (ie, aperistalsis with simultaneous contractions, undetectable lower esophageal sphincter pressure) at esophageal manometry. She is currently on proton pump inhibitors and complains of mild recurrent digestive symptoms.

Analysis of the pedigree revealed other cases of consanguinity and clinical cases suggestive of digestive disorders. Two cousins of the investigated subjects (IV-14, IV-15) died at ages 19 and 15 years, respectively, because of allegedly digestive disorders compatible with the diagnosis of pseudo-obstruction. The female cousin (IV-15) had clinical and radiological evidence of CIIP, growth retardation, malnutrition, megaduodenum, esophageal dysmotility (aperistalsis and undetectable lower esophageal sphincter pressure), renal hypoplasia, vescico-urethral reflux, ascites, and unspecified granulomatous hepatitis. She died outside the hospital for unknown causes. Her brother (IV-14) died of what was described as a 'similar disease', but no clinical reports are available. Two of their sisters and one brother are well and alive. Two other patients (IV-1, IV-2) who were the offspring of another consanguineous marriage died at ages 14 and 15 years, respectively, before they could be investigated. Relatives reported that they were affected by abdominal distension, diarrhea, and recurrent abdominal pain. Their brother and sister are alive and well.

Subject V-4 is a 4-year-old girl characterized by growth retardation, but no biochemical or endocrinological abnormalities. Bowel function is clinically normal. She had one abdominal pain attack and no positive radiologic finding (notably CIIP subocclusive episodes in affected individuals of this family appeared at 10-11 years of age). Subject V-5 is an 18-year-old boy with hyperkinetic behavior, but no obvious digestive problems.

\section{Histopathology}

Compared to controls, immunohistopathological analysis of gut full-thickness biopsies obtained from case IV-9 and IV-10 showed changes in the intrinsic innervation characterized by neuronal loss as identified by NSE (Figure 2) and NF immunolabeling along with severe neurochemical depletion of neuronal nitric oxide synthase (Figure 2), vasoactive intestinal polypeptide, substance P/tachykinin, neuropeptide $\mathrm{Y}$, calcitonin gene-related peptide, galanin, suggesting derangement of both inhibitory, and excitatory neurons. Furthermore, BCL-2 expression (a protein involved in the regulatory mechanisms underlying cell survival) was readily detectable in myenteric, submucosal, and nerve processes of the control small intestine, whereas BCL-2 was markedly reduced in enteric neurons of the affected individuals. KIT immunoreactivity (marker for intersitial cells of Cajal, ICC) showed a reduced ICC network around myenteric plexuses and within smooth muscle layer as compared to the normal immunoreactive staining of controls. Finally, compared to controls, $\alpha$-actin immunoreactivity is decreased in both circular and longitudinal layers, suggesting smooth muscle involvement. In contrast, compared to controls, the enteroglial cell marker protein S-100 showed an apparently normal immunoreactive pattern in patients (Figure 2).

Long-segment Barrett esophagus has been confirmed by evidence of goblet cells with intestinal metaplasia.

\section{Genetic mapping}

Through the genome-wide scan of the central portion of the pedigree (see Materials and methods) we identified a candidate region on chromosome 8q23-q24 between markers D8S285 and D8S272 $(72 \mathrm{Mb}, 68.9 \mathrm{cM})$ that gave a maximum two-point LOD score of 1.96 at $\theta=0.0$ for marker D8S1784 and a maximum multipoint LOD score of 2.55 at $3.90 \mathrm{cM}$ from marker D8S1784. To confirm and further evaluate the locus on chromosome $8 \mathrm{q} 23-\mathrm{q} 24$, we extended the analysis to all the available individuals in the family (Figure 1) and we genotyped the entire family for 14 additional microsatellite markers located between markers D8S270 and D8S272. Some of these markers had not previously been described and were designed ad hoc for this study (Table 1). By means of this approach we obtained a 

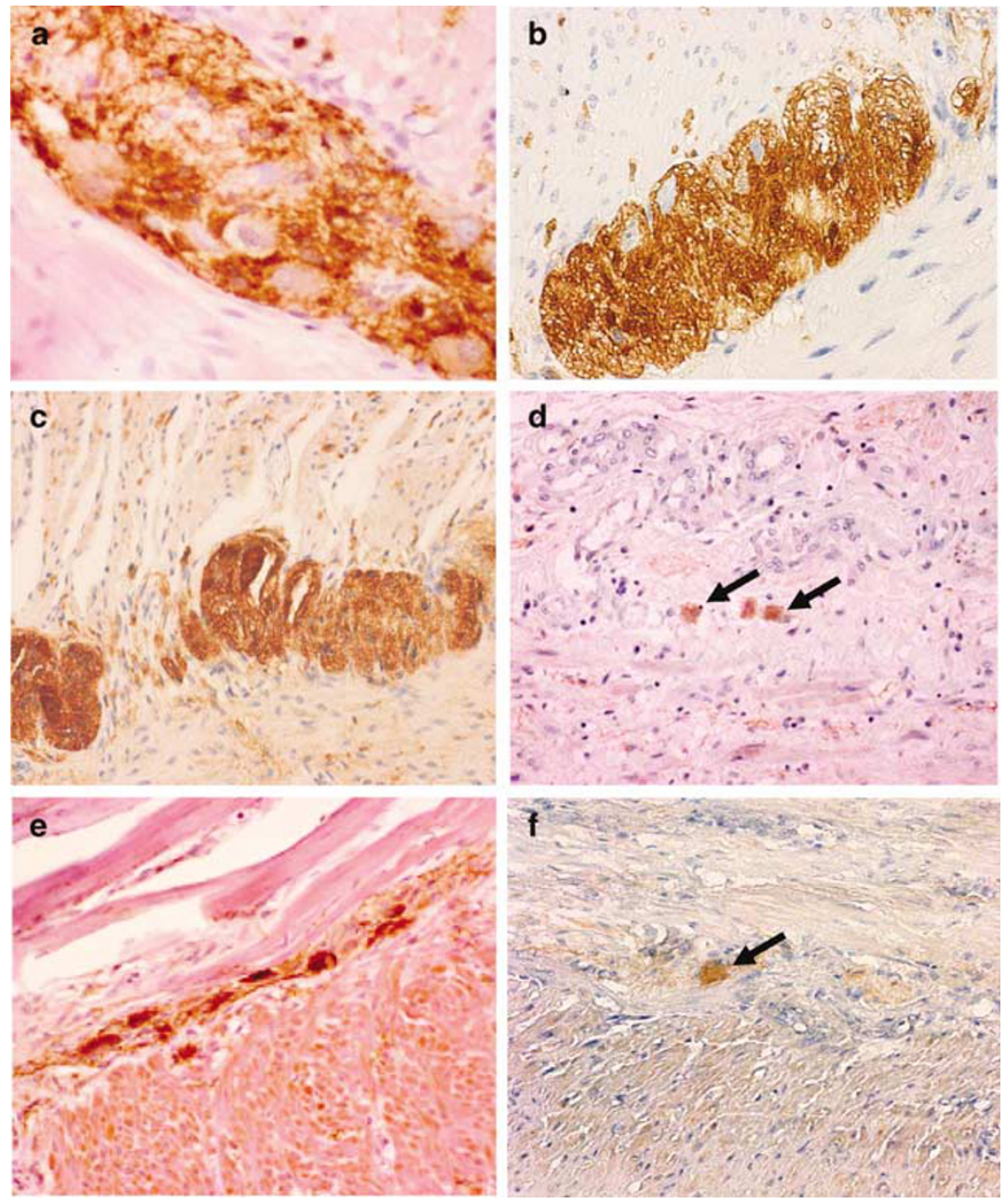

Figure 2 Representative examples showing the enteric glial marker protein S-100 (a, b), the general neuronal marker NSE (c, d) and the nNOS $(\mathbf{e}, \mathbf{f})$ immunoreactivities in the neuromuscular layer of the jejunum of a family member (IV-9) affected with the syndromic CIIP (b, $\mathbf{d}, \mathbf{f})$ as compared with an age-sex-matched control subject (a, c, e). Note the apparently normal S-100 labeling in enteroglial cells encircling myenteric neurons in the patient (b) as compared to the control (a). Remarkably, there was a marked reduction of NSE (arrows) and nNOS (arrow) immunoreactive neural network in the myenteric plexus and in nerve fibers targeting the muscular layer in the patient ( $\mathbf{d}$ and $\mathbf{f}$, respectively) compared to the control (c and $\mathbf{e}$, respectively). Streptavidin biotin immunoperoxidase technique. Original magnifications: $\times 200(\mathbf{a}$ and $\mathbf{b}), \times 100(\mathbf{c}-\mathbf{f})$.

maximum two-point LOD score of 3.97 for marker NT_008046_6 (Table 3) and a maximum multipoint LOD score of 5.01 (data not shown).

The genotyping of these new markers allowed us to refine the chromosomal interval of the CIIP locus on the long arm of chromosome 8 . The centromeric boundary was positioned between marker NT_008046_1 (recombinant in III-1) and the non-recombinant marker NT_008046_2. Instead, the telomeric boundary is now defined by the non-recombinant marker NT_008046_6 and by a newly identified CA-repeat (NT_008046_7) that shows recombination in individual V-4 as shown in Figure 1.

As reported in Figure 3, the critical interval spans about $13 \mathrm{Mb}$ and contains 8 markers (all homozygous), 21 known genes, and 12 predicted genes.

\section{Exclusion of candidate genes}

The three investigated genes (ie, SLC3OA8, COLEC10, and SNTB1) did not show any mutation in their coding regions.

\section{Discussion}

In our study, we provided strong evidence for the location of a recessive CIIP-predisposition gene on chromosome $8 \mathrm{q} 23-\mathrm{q} 24$. Since the histopathological findings in the two studied patients suggested a neuromuscular involvement, we investigated possible candidate genes from this region whose expression seemed compatible with the above findings. We focused our interest on some candidate genes, namely SLC3OA8 (a zinc transporter), ${ }^{27}$ COLEC10 
Table 3 Two-Point LOD scores for markers in (indicated in bold) and around the candidate region

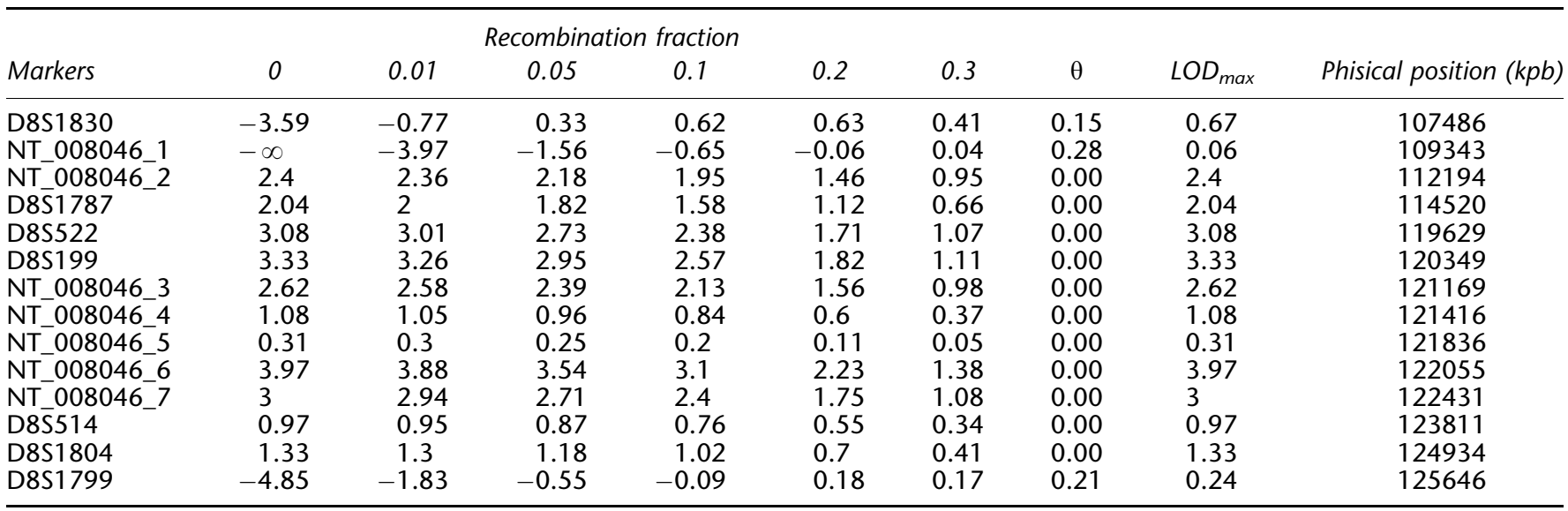

\section{Physical Map of the Critical Region}

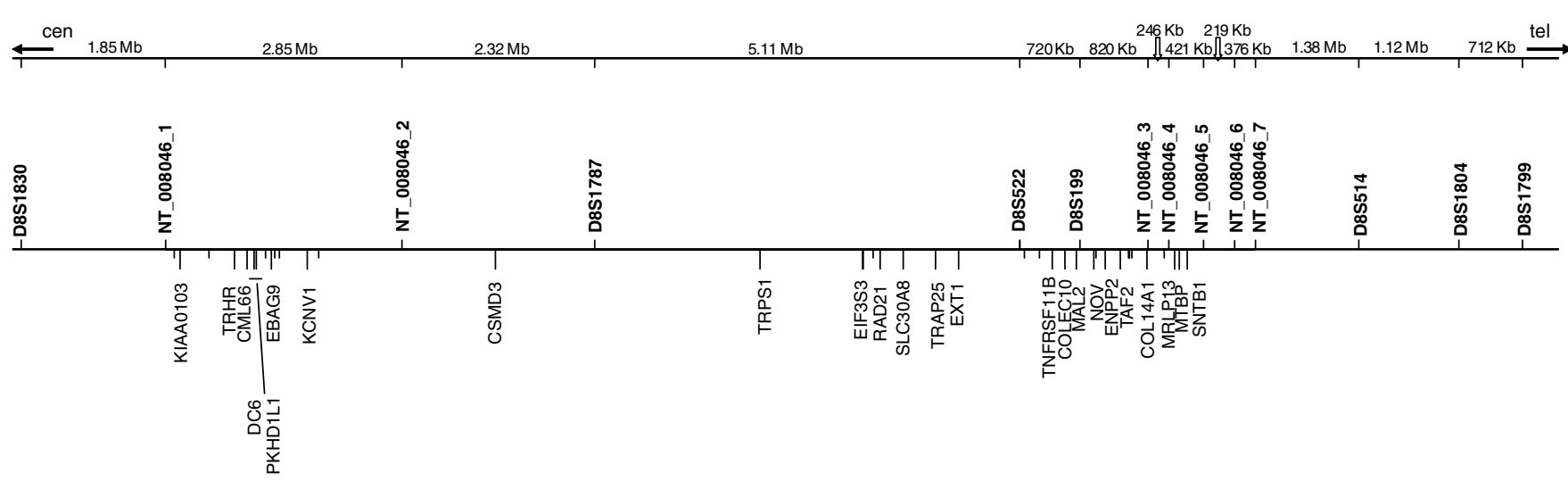

Figure 3 Physical map of the critical region on chromosome 8.

(a member of the C-lectin family, which includes proteins that possess collagen-like sequences and carbohydrate recognition domains), ${ }^{28}$ and SNTB1 (a dystrophin-associated protein). ${ }^{29}$ Sequence analysis excluded all these genes as responsible for this new syndromic CIIP associated with Barrett esophagus.

Identification of the gene responsible for this syndromic CIIP would be of pivotal importance to understand the pathological mechanisms underlying intestinal pseudoobstructive syndromes. Indeed, the vast majority of CIIP cases appear to be sporadic in origin resulting from a multifactorial pathogenesis, whereas only few cases are clearly monogenic disorders. So far, at least four different genetic causes of syndromic CIIP have been identified. These include a locus in Xq28 ${ }^{13,14}$ and three identified genes, namely the TP/ECGF1 gene, ${ }^{16} P O L G,{ }^{17}$ and SOX $10 .{ }^{18}$ Notably, the three patients (two brothers and one maternal uncle) reported by FitzPatrick et al ${ }^{14}$ were affected by syndromic CIIP associated with patent ductus arteriosus and thrombocytopenia with large platelets (detected only in the two brothers). Molecular studies in these patients showed an Xq28 haplotype segregating with the disease. Compared with the family described by Auricchio et al ${ }^{13}$ showing CIIP, malrotation and pyloric hypertophic stenosis, the additional cardiac abnormalities identified in the family reported by FitzPatrick et l $^{14}$ may be the result of an Xq28 microdeletion, or, alternatively, may indicate the existence of a CIIP gene located on chromosome $\mathrm{X}$ playing a role in developmental regulation of several organs. This latter possibility is in agreement with the findings obtained in the family herein described, in which the recessive monogenic complex phenotype is likely due to a single gene mutation. Several examples of single gene mutation underlying syndromic CIIP have been documented. Bott et $a l^{30}$ described the association between X-linked hydrocephalus with stenosis of the aqueduct of Sylvius and CIIP in an infant carrying a L1CAM gene mutation affecting the fibronectin type III 
domain of the L1CAM protein. Since L1CAM controls ICC differentiation, its mutation may explain the severe impairment of gut motility as a result of ICC loss reported in this pediatric patient. ICC depletion was also identified in intestinal tissues obtained from affected members of the family herein reported. Similarly, gut motility failure observed in the affected members of this family may be related to mutations in one of the genes involved in ICC differentiation.

Other single gene mutations have been identified in syndromic CIIP. Indeed, TP mutations are known to cause mitochondrial neurogastrointestinal encephalopathy (MNGIE), ${ }^{16}$ a multisystem disorder clinically characterized by onset between the second and fifth decades of life and a variety of symptoms such as ptosis, progressive external ophthalmoplegia, CIIP, diffuse leukoencephalopathy, peripheral neuropathy and myopathy. A form of MNGIE without leukoencephalopathy can be caused by a mutation in the POLG gene. ${ }^{17}$ Finally, a mutation in SOX10 has been reported in a family with peripheral neuropathy characterized by hypomyelination who had deafness and CIIP. ${ }^{18}$ Interestingly, this family did not show any member with Hirschsprung disease or pigmentary abnormalities, two features reported in Waardenburg-Shah syndrome associated with SOX10 mutations. This evidence indicates that SOX10 exert a pivotal role in the development of two neural crest-derived human cell lineages. Taken together both genes involved in MNGIE and SOX10 related CIIP indicate a neuromuscular impairment underlying gut dysmotility. Because histopathologic data obtained in members of the family herein reported suggest neuromuscular abnormalities as a mechanism underlying CIIP, it is likely that a gene controlling muscular and/or neuronal differentiation and morpho-functional integrity may be responsible for such syndromic form of severe dysmotility.

The identification of the gene responsible for this syndromic form of pseudo-obstruction could add clues also to the understanding of the pathogenesis of an additional frequent and severe disorder such as Barrett esophagus, which has been associated, for the first time, to CIIP. Barrett esophagus is a metaplasic condition in which the normal squamous cells that line the esophagus turn into specialized intestinal-like columnar cells at the gastroesophageal junction. Barrett esophagus and, especially, long-segment forms of such metaplasia represent the only known precursor of esophageal adenocarcinoma. It has been suggested that the development of Barrett esophagus is a two-step process, beginning with the conversion of distal esophageal mucosa to cardiac-type epithelium and then with the 'intestinalization' of this underlying cardiac epithelium. ${ }^{31}$ The cell of origin of Barrett epithelium is unknown. ${ }^{32}$ It has been hypothesized that Barrett esophagus originates from the migration of gastric cells, but also that it derives from a multipotent cell still present in the proliferative layer of the esophageal epithelium. Barrett esophagus could be a congenital condition resulting from an incomplete process of embryonic epithelization (the embryonic columnar cells would not be substituted by squamous cells) or it could be caused by gastro-esophageal reflux (a condition, often associated with Barrett esophagus) that damages and inflames the normal epithelium thus inducing metaplasia. ${ }^{30,31}$ In this respect, the family members affected with syndromic CIIP associated with long-segment Barrett esophagus presented a complete lack of sphincteric activity at the esophago-gastric junction. It is likely that their Barrett epithelium was associated with severe gastroesophageal reflux which, in turn, could reflect an underlying generalized impairment of gastrointestinal motility. A genetic locus for gastro-esophageal reflux associated with Barrett esophagus has already been mapped on chromosome 13 but the gene has not been identified yet. ${ }^{33}$

Other familial cases of CIIP should now be examined for linkage to chromosome $8 \mathrm{q} 23-\mathrm{q} 24$, as well as families with Barrett esophagus and impairment of the intestinal propulsion to further narrow the candidate region and to confirm a possible relationship between CIIP and other diseases or conditions (particularly Barrett esophagus). CIIP and Barrett esophagus are serious pathological conditions of the gastrointestinal tract. The former causes severe impairment of digestive functions up to intestinal failure, while the latter is linked to an increased risk of esophageal adenocarcinoma. Identification of a specific gene mutation(s) associated with these currently intractable diseases would open new perspectives for managing patients with such disorders.

\section{Note added in proof}

During the revision of the present manuscript the gene responsible for the $\mathrm{x}$-linked form of CIIP described by Auriccihio et al., has been identified as the FLNA gene ( $A m J$ Hum Genet 2007; 80 (4): 752-758).

\section{Acknowledgements}

This work was supported by the Italian Ministry of Education, University and Research (COFIN Project No. 2004062155 to RDeG, 2004055120 to $G B$ and 2003064378 to RDeG, GB and VS), by grants from FIRB Italian Ministry of Education, University and Research and from the European Commission (Project QLRT-2000-01646) to GR.

\footnotetext{
References

1 Malagelada JR, Camilleri M, Stanghellini V: Manometric Diagnosis of Gastrointestinal Motility Disorders. New York: Thieme, 1986.

2 Stanghellini V, Corinaldesi R, Barbara L: Pseudo-obstruction syndromes. Baillieres Clin Gastroenterol 1988; 2: 225-254.

3 De Giorgio R, Stanghellini V, Barbara G et al: Primary enteric neuropathies underlying gastrointestinal motor dysfunction. Scand J Gastroenterol 2000; 35: 114-121.
} 
4 Stanghellini V, Cogliandro R, De Giorgio R et al: Natural history of chronic idiopathic intestinal pseudo-obstruction in adults: a single center study. Clin Gastroenterol Hepatol 2005; 3: 449-458.

5 Camilleri M, Phillips SF: Acute and chronic intestinal pseudoobstruction. Adv Intern Med 1991; 36: 287-306.

6 Di Lorenzo C: Pseudo-obstruction: current approaches. Gastroenterology 1999; 116: 980-987.

7 Coulie B, Camilleri M: Intestinal pseudo-obstruction. Annu Rev Med 1999; 50: 37-55.

8 Krishnamurthy S, Schuffler MD: Pathology of neuromuscular disorders of the small intestine and colon. Gastroenterology 1987; 93: 610-639.

9 De Giorgio R, Sarnelli G, Corinaldesi R, Stanghellini V: Advances in our understanding of the pathology of chronic intestinal pseudo-obstruction. Gut 2004; 53: 1549-1552.

10 Schuffler MD, Pope CE: Studies of idiopathic intestinal pseudoobstruction. II. Hereditary hollow visceral myopathy: family studies. Gastroenterology 1977; 73: 339-344.

11 Roper EC, Gibson A, McAlindon ME et al: Familial visceral neuropathy: a defined entity? Am J Med Genet 2005; 137: 249-254.

12 Tanner MS, Smith B, Lloyd JK: Functional intestinal obstruction due to deficiency of argyrophil neurones in the myenteric plexus. Familial syndrome presenting with short small bowel, malrotation, and pyloric hypertrophy. Arch Dis Chil 1976; 51: 837-841.

13 Auricchio A, Brancolini V, Casari G et al: The locus for a novel syndromic form of neuronal intestinal pseudoobstruction maps to Xq28. Am J Hum Genet 1996; 58: 743-748.

14 FitzPatrick DR, Strain L, Thomas AE et al: Neurogenic chronic idiopathic intestinal pseudo-obstruction, patent ductus arteriosus, and thrombocytopenia segregating as an X-linked recessive disorder. J Med Genet 1997; 34: 666-669.

15 De Giorgio R, Seri M, Cogliandro R et al: Analysis of candidate genes for intrinsic neuropathy in a family with chronic idiopathic intestinal pseudo-obstruction. Clin Genet 2001; 59: $131-133$.

16 Nishino I, Spinazzola A, Hirano M: Thymidine phosphorylase gene mutations in MNGIE, a human mitochondrial disorder. Science 1999; 283: 689-692.

17 Van Goethem G, Schwartz M, Lofgren A, Dermaut B, Van Broeckhoven C, Vissing J: Novel POLG mutations in progressive external ophthalmoplegia mimicking mitochondrial neurogastrointestinal encephalomyopathy. Eur J Hum Genet 2003; 11: $547-549$.

18 Pingault V, Girard M, Bondurand N et al: SOX10 mutations in chronic intestinal pseudo-obstruction suggest a complex physiopathological mechanism. Hum Genet 2002; 111: 198-206.
19 Mungan Z, Akyuz F, Bugra Z et al: Familial visceral myopathy with pseudo-obstruction, megaduodenum, Barrett's esophagus, and cardiac abnormalities. Am J Gastroenterol 2003; 98: 2556-2560.

20 De Giorgio R, Barbara G, Stanghellini V et al: Clinical and morphofunctional features of idiopathic myenteric ganglionitis underlying severe intestinal motor dysfunction: a study of three cases. Am J Gastroenterol 2002; 97: 2454-2459.

21 Hockenbery D, Nunez G, Milliman C, Schreiber RD, Korsmeyer SJ: Bcl-2 is an inner mitochondrial membrane protein that blocks programmed cell death. Nature 1990; 348: 334-336.

22 Kruglyak L, Daly MJ, Reeve-Daly MP, Lander ES: Parametric and nonparametric linkage analysis: a unified multipoint approach. Am J Hum Genet 1996; 58: 1347-1363.

23 O'Connell JR, Weeks DE: PedCheck: a program for identification of genotype incompatibilities in linkage analysis. Am J Hum Genet 1998; 63: 259-266.

24 Thiele H, Nurnberg P: HaploPainter: a tool for drawing pedigrees with complex haplotypes. Bioinformatics 2005; 21: 1730-1732.

25 Lathrop GM, Lalouel JM, Julier C, Ott J: Strategies for multilocus linkage analysis in humans. Proc Natl Acad Sci USA 1984; 81: $3443-3446$.

26 Sobel E, Lange K: Descent graphs in pedigree analysis: applications to haplotyping, location scores, and marker-sharing statistics. Am J Hum Genet 1996; 58: 1323-1337.

27 Seve M, Chimienti F, Devergnas S, Favier A: In silico identification and expression of SLC30 family genes: an expressed sequence tag data mining strategy for the characterization of zinc transporters' tissue expression. BMC Genomics 2004; 5: 32.

28 Ohtani K, Suzuki Y, Eda S et al: Molecular cloning of a novel human collectin from liver (CL-L1). I Biol Chem 1999; 274: 13681-13689.

29 Yoshizawa K, Inaba K, Mannen H, Kikuchi T, Mizutani M, Tsuji S Analyses of beta-1 syntrophin, syndecan 2 and gem GTPase as candidates for chicken muscular dystrophy. Exp Anim 2003; 52: 391-396.

30 Bott L, Boute O, Mention K, Vinchon M, Boman F, Gottrand F: Congenital idiopathic intestinal pseudo-obstruction and hydrocephalus with stenosis of the aqueduct of Sylvius. Am J Med Genet 2004; 130: 84-87.

31 Peters JH, Hagen JA, DeMeester SR: Barrett's esophagus. J Gastrointest Surg 2004; 8: 1-17.

32 Flejou JF: Barrett's oesophagus: from metaplasia to dysplasia and cancer. Gut 2005; 54 (Suppl 1): i6-i12.

$33 \mathrm{Hu}$ FZ, Preston RA, Post JC et al: Mapping of a gene for severe pediatric gastroesophageal reflux to chromosome 13q14. JAMA 2000; 284: $325-334$. 